ORIGINAL ARTICLE

\title{
Long term follow up after meningitis in infancy: behaviour of teenagers
}

\author{
S Halket, J de Louvois, D E Holt, D Harvey
}

Arch Dis Child 2003;88:395-398

See end of article for authors' affiliations

.....................

Correspondence to: Professor D Harvey, Department of Paediatrics, Imperial College School of Medicine, Hammersmith Hospital, Du Cane Road, London W12 ONN, UK;

david.harvey@imperial.ac.uk

Accepted 25 September 2002

\begin{abstract}
Aims: To determine the effects of meningitis in infancy on subsequent teenage behaviour. Methods: A national postal survey of parents and teachers using an established standard behavioural questionnaire. Subjects were 739 of the surviving children from the national incidence study of infantile meningitis in England and Wales carried out between 1985 and 1987, together with a group of 606 matched controls that had been recruited when the index cases were 5 years old.

Results: $46 \%$ of parents of children who had had meningitis with complications in infancy, compared with $21 \%$ of parents of control children rated their children as having behavioural problems. When the children were rated by their teachers, $37 \%$ and $23 \%$ respectively, were scored as having behavioural problems. There was no significant difference in behaviour between the 103 children who had had meningitis during the first month of life and the 634 who had had postneonatal meningitis. Eight of the index children had been excluded from school compared to none from the control group.

Conclusions: The behaviour of teenage children who had meningitis in infancy is worse than that of control children who did not have infantile meningitis when rated by parents and teachers.
\end{abstract}

$\mathrm{T}$ he subjects of this study were the survivors from a national incidence study of infantile meningitis in England and Wales, carried out by de Louvois and colleagues ${ }^{1}$ between 1985 and 1987. The effects of meningitis on the overall health of these children at the age of 5 has been reported, ${ }^{2}$ and also the cognitive outcome at 9 years of age of 111 children who had neonatal meningitis. ${ }^{3}$ The reluctance of some families to take part in the latter study, because of the adverse behaviour of their child, prompted us to review the behaviour of the whole group, and to compare the results with those from the controls who had been recruited at the time of the 5 year follow up study. There are no other published reports on behaviour following meningitis in such a large group of patients and none relating to a national cohort.

\section{SUBJECTS AND METHODS}

From our original study there were 1175 survivors on whom we had information from the parents and/or general practitioner (GP) when the child was aged 5 years. All of these children had had proven bacterial meningitis before their first birthday. A postal questionnaire about behaviour was sent to the parents and, following permission from the family, to the appropriate schoolteacher. The families were traced if necessary via their GP and relevant health authority.

The Strengths and Difficulties Questionnaire (SDQ) was used to evaluate behaviour. ${ }^{4}$ This is a brief form containing 25 questions, which can be completed in five minutes by the parents or teachers of children aged 4 to 16 . The SDQ is based on the long established and highly respected Rutter behavioural screening questionnaire, ${ }^{5}$ and has been favourably compared with the widely used Child Behaviour Checklist. ${ }^{67}$ The 25 questions in the SDQ are divided into five categories: emotional symptoms; conduct problems; hyperactivity; peer problems; and prosocial behaviour; each category contains five questions. The first four of these groups rate negative aspects of behaviour and the fifth, the prosocial group, rates positive aspects, for example, being considerate, sharing, kind, or helpful. The person completing the form was asked to answer each question as "not true", "somewhat true", or "certainly true". "Somewhat true" was always scored as 1, but the scoring of "not true" and "certainly true" varies with each item, being equal to either 0 or 2 .
The scores from the first four groups of antisocial behaviour were added to give a "total deviance" score. A total deviance score of between 0 and 13 was considered "normal" and between 14 and 40 was "not normal". The "prosocial" behaviour score was considered "normal" between 10 and 6 and "not normal" if 5 or less.

There were also questions relating to the impact the child's behaviour had on the family or classroom. Parents were asked if their child experienced difficulties that interfered with their life at home, with friendships, classroom learning, and leisure activities. They were also asked if these difficulties imposed a burden on family life. Questions on home life and leisure activities were omitted from the teacher's forms. Parents and teachers were asked to rate the extent of the difficulties on everyday life as "not at all", "only a little", "quite a lot", or "a great deal". "Not at all" and "only a little" were then scored as 0 , "quite a lot" scored 1 , and "a great deal" scored 2 . The "total impact" was calculated as the sum of the five scores; the maximum burden being ten for parents and six for teachers.

The teachers were not told by us whether or not the child had had meningitis, although some had been told by the parents. At the time of the five year follow up, a cohort of matched (for age and sex) controls had been collected. The control children had been recruited by what was then known as the Family Health Services Agency. Each control child was selected from the same GP list as an index child. These control children were again traced and identical questionnaires sent to their parents and teachers.

Permission for this project was given by the research ethics committee of the Royal Postgraduate Medical School, and if required, permission was also obtained from other local research ethics committees.

\section{Data analysis}

Data handling and statistical analyses were carried out using EpiInfo (version 6) from the Division of Surveillance and Epidemiology, Epidemiology Program Office, Centre for Disease Control and Prevention, Atlanta, GA 30333, USA.

\section{RESULTS}

Of the 1175 post-meningitic children reviewed at 5 years of age, there were 178 who were lost to further follow up. Of 
Table 1 Type of education received by index cases and controls at 13 years of age

\begin{tabular}{lccc}
\hline Type of school & $\begin{array}{l}\text { Complicated } \\
\text { meningitis } \\
\mathrm{n}(\%)\end{array}$ & $\begin{array}{l}\text { Uncomplicated } \\
\text { meningitis } \\
\mathrm{n}(\%)\end{array}$ & $\begin{array}{l}\text { Control } \\
\mathrm{n}(\%)\end{array}$ \\
\hline Mainstream & $252(85)$ & $299(90)$ & $367(98)$ \\
Help at school & $14(5)^{*}$ & $14(4)$ & $8(2)$ \\
Special school & $24(8) \dagger$ & $15(5) \ddagger$ & $1(<1)$ \\
Excluded & $5(2)$ & $3(<1)$ & 0 \\
Subtotal & 295 & 331 & 376 \\
No information & 53 & 60 & 104 \\
Total & 348 & 391 & 480 \\
\hline
\end{tabular}

${ }^{*} \mathrm{RR}=2.41,95 \% \mathrm{Cl}=1.02$ to $5.69, \chi^{2}=4.3, \mathrm{p}<0.05$.

†RR $=33.1,95 \% \mathrm{Cl}=4.5$ to $243.5, \chi^{2}=30.8, \mathrm{p}<0.001$

$\ddagger R R=18.4,95 \% \mathrm{Cl}=2.4$ to $138.8, \chi^{2}=15.7, \mathrm{p}<0.001$.

(All values are compared with controls)

these there were 81 on whom we had a GP response at age 5, but no permission to contact the family. There were 25 who did not reply when contacted for our nine year follow up. A further 69 could not be traced despite contact with the relevant health authority, and three had died. Completed questionnaires were received from 739 (74\%) of the remaining 997 index cases and from 480/785 (61\%) of the control parents; $84 \%$ of parents of index cases and $78 \%$ of control parents gave us permission to contact the child's school; $77 \%$ of teachers of index cases and $94 \%$ of control teachers replied. The mean ages of the children who had had meningitis (index cases) and the control children were both 13.3 (SD 0.4) years.

The study carried out when the index cases were 5 years old, allocated children to one of four categories of disability (severe, moderate, mild, or none). A classification of severe disability included children having multiple problems such as severe neuromotor impairment, significant intellectual impairment, severe seizure disorders, and severe visual or auditory impairment. Children were classed as having a moderate disability if their disability impaired their functioning but was not associated with severe intellectual or developmental impairment. This group included children with mild neuromotor disabilities, intellectual impairment, moderate sensorineural hearing loss, mild or moderate visual impairment, epilepsy that was controlled with treatment, and hydrocephalus without complications. Children classified as having mild disorders included those with middle ear disease, squint, febrile convulsions, and behavioural problems. Children were classed as having no disability if there was no evidence of developmental problems.

There were 436 index cases on which information had been collected at age 5, but for whom there was no behaviour assessment. The disability classification for these children at age 5 showed $242(56 \%)$ to be normal, $121(28 \%)$ to have mild disability, $36(8 \%)$ to have moderate disability, and $37(9 \%)$ to have severe disability. This compares with figures of 55\%, 29\%, $12 \%$, and $4 \%$ respectively among the 739 subjects of this study. There is a significant difference in the proportion of severely disabled children whose parents did not respond or could not be traced and those who did respond (relative risk (RR) 1.51, confidence interval (CI) 1.20 to $1.90, \mathrm{p}<0.05)$.

Information collected in the incidence study ${ }^{1}$ was used to divide the index children into two groups- "complicated" and "uncomplicated" meningitis. The criteria used for inclusion in the "complicated" group were one or more of the following: meningitis diagnosed at less than 28 days, together with a birth weight of less than $2000 \mathrm{~g}$; coma; convulsions; hydrocephalus; a temperature of $>40^{\circ} \mathrm{C}$; ventriculitis; relapse. There were 348 children with "complicated" and 391 with "uncomplicated" meningitis.

Table 1 shows the type of education the children were receiving at 13 years of age. Thirty nine index children ( $8 \%$ of
Table 2 Results of the Strengths and Difficulties Questionnaire-total deviance

\begin{tabular}{lccc}
\hline & $\begin{array}{l}\text { Complicated } \\
\text { meningitis } \\
\mathrm{n}(\%)\end{array}$ & $\begin{array}{l}\text { Uncomplicated } \\
\text { meningitis } \\
\mathrm{n}(\%)\end{array}$ & $\begin{array}{l}\text { Control } \\
\mathrm{n}(\%)\end{array}$ \\
\hline $\begin{array}{l}\text { Parent's response } \\
\text { Total deviance }\end{array}$ & & & \\
$\quad$ Not normal & $158(46)^{*}$ & $147(38) \dagger$ & $101(21)$ \\
$\quad$ Normal & $187(54)$ & $244(62)$ & $379(79)$ \\
Subtotal & 345 & 391 & 480 \\
No information & 3 & 0 & 0 \\
Total & 348 & 391 & 480 \\
Teacher's response & & & $80(23)$ \\
Total deviance & & $101(33) \S$ & $271(77)$ \\
$\quad$ Not normal & $98(37) \ddagger$ & $205(67)$ & 351 \\
$\quad$ Normal & $167(63)$ & 306 & 129 \\
Subtotal & 265 & 85 & 480 \\
No information & 83 & 391 & \\
Total & 348 & & \\
\hline
\end{tabular}

${ }^{*} \mathrm{RR}=2.18,95 \% \mathrm{Cl}=1.77$ to $2.68, \chi^{2}=57.0, \mathrm{p}<0.001$.

tRR $=1.79,95 \% \mathrm{Cl}=1.44$ to $2.22, \chi^{2}=29.0, p<0.001$

$\ddagger R R=1.62,95 \% \mathrm{Cl}=1.27$ to $2.08, \chi^{2}=14.8, \mathrm{p}<0.001$.

$\S R R=1.45,95 \% \mathrm{Cl}=1.13$ to $1.86, \chi^{2}=8.5, \mathrm{p}<0.05$.

the "complicated" cases and 5\% of "uncomplicated" meningitis cases) compared to one control child attended a special school. There was a statistically significant difference between the "uncomplicated" meningitis group receiving extra help at school $(14 / 348,5 \%)$ and the control group $(8 / 480,2 \%)$ (RR 2.41, CI 1.02 to 5.69, p < 0.05). The difference between index and control children attending a special school was highly significant for both the "complicated" (RR 33.1, CI 4.5 to $243.5, \mathrm{p}<0.001$ ) and the "uncomplicated" group (RR 18.4, CI 2.4 to $138.8, \mathrm{p}<0.001)$. Eight children had a school exclusion order; all were boys and all were from the index group. Permission to contact the child's school was refused by 113 parents of the index cases and 104 parents of control children.

Tables 2 and 3 summarise the overall results of the SDQ. It can be seen that the greatest difference was in the "total deviance", when rated by parents, between the "complicated" meningitis group and controls (table 2; RR 2.18, CI 1.77 to $2.68, \mathrm{p}<0.001)$, although the difference between the "uncomplicated" cases and controls was also significant (RR 1.79 , CI 1.44 to $2.22, \mathrm{p}<0.001)$. The teacher rated total deviance score was "not normal" in 37\% of the "complicated" cases (RR 1.62, CI 1.27 to $2.08, \mathrm{p}<0.001$ ), and $33 \%$ of the

Table 3 Results of the Strengths and Difficulties Questionnaire-impact score

\begin{tabular}{lccc}
\hline & $\begin{array}{l}\text { Complicated } \\
\text { meningitis } \\
\mathrm{n}(\%)\end{array}$ & $\begin{array}{l}\text { Uncomplicated } \\
\text { meningitis } \\
\mathrm{n}(\%)\end{array}$ & $\begin{array}{l}\text { Control } \\
\mathrm{n}(\%)\end{array}$ \\
\hline $\begin{array}{l}\text { Parent's response } \\
\text { Impact score }\end{array}$ & & & \\
$\quad$ Not normal & $118(35)^{*}$ & $96(25) \dagger$ & $47(10)$ \\
$\quad$ Normal & $215(65)$ & $287(75)$ & $414(90)$ \\
Subtotal & 333 & 383 & 461 \\
No information & 15 & 8 & 19 \\
Total & 348 & 391 & 480 \\
Teacher's response & & & \\
Impact score & & $103(35) \S$ & $82(24)$ \\
$\quad$ Not normal & $98(38) \ddagger$ & $195(65)$ & $259(76)$ \\
$\quad$ Normal & $158(62)$ & 298 & 341 \\
Subtotal & 256 & 93 & 139 \\
No information & 92 & 391 & 480 \\
Total & 348 & & \\
\hline
\end{tabular}

${ }^{*} \mathrm{RR}=3.48,95 \% \mathrm{Cl}=2.56$ to $4.73, \chi^{2}=74.7, \mathrm{p}<0.001$ tRR $=2.46,95 \% \mathrm{Cl}=1.78$ to $3.39, \chi^{2}=32.8, \mathrm{p}<0.001$ $\ddagger R R=1.59,95 \% \mathrm{Cl}=1.25$ to $2.03, \chi^{2}=14.0, \mathrm{p}<0.001$. $\S R R=1.44,95 \% \mathrm{Cl}=1.13$ to $1.84, \chi^{2}=8.5, p<0.05$. 
Table 4 Combined parent and teacher total deviance ratings

\begin{tabular}{|c|c|c|c|c|c|c|}
\hline & $\begin{array}{l}\text { Index } \\
\text { n (\%) }\end{array}$ & $\begin{array}{l}\text { GP control } \\
n(\%)\end{array}$ & RR & $95 \% \mathrm{Cl}$ & $\chi^{2}$ & $\mathrm{p}$ \\
\hline Parent and teacher rate as normal & $267(36)$ & $239(50)$ & 0.73 & 0.64 to 0.83 & 22.4 & $<0.001$ \\
\hline Parent and teacher rate as not normal & $134(18)$ & $40(8)$ & 2.18 & 1.56 to 3.04 & 22.8 & $<0.001$ \\
\hline Parent rates as normal, teacher as not normal & $61(8)$ & $40(8)$ & 0.99 & 0.68 to 1.45 & 0.00 & 0.96 \\
\hline Parent rates as not normal, teacher rates as normal & $103(14)$ & $32(7)$ & 2.09 & 1.43 to 3.06 & 15.6 & $<0.001$ \\
\hline No information & $174(24)$ & $129(27)$ & & & & \\
\hline Total & 739 & 480 & & & & \\
\hline
\end{tabular}

Table 5 Numbers of children having normal prosocial scores

\begin{tabular}{|c|c|c|c|c|c|c|}
\hline & $\begin{array}{l}\text { Index } \\
\text { n (\%) }\end{array}$ & $\begin{array}{l}\text { Control } \\
\text { n (\%) }\end{array}$ & RR & $\mathrm{Cl}$ & $\chi^{2}$ & $p$ \\
\hline Parents & $625 / 736(85)^{*}$ & $437 / 480(91) \dagger$ & 0.82 & 0.73 to 0.91 & 9.8 & $<0.05$ \\
\hline Teachers & $360 / 567$ (63) & $249 / 351$ (71) & 0.88 & 0.80 to 0.98 & 5.4 & $<0.05$ \\
\hline
\end{tabular}

"uncomplicated" meningitis cases (RR 1.45, CI 1.13 to 1.86 , $p<0.05$ ), compared with $23 \%$ of controls. Results of the "impact scores" (table 3 ) showed that parents whose children had "complicated" meningitis were three times more likely to report a negative impact on home and social life than parents of control children (RR 3.48, CI 2.56 to $4.73, \mathrm{p}<0.001$ ). The teacher rated impact scores showed a less marked, but significant difference between the "complicated" meningitis group and control children (RR 1.59, CI 1.25 to $2.03, \mathrm{p}<0.001$ ), and between the "uncomplicated" meningitis group and controls (RR 1.44, CI 1.13 to $1.84, \mathrm{p}<0.05$ ).

The behaviour of those children attending a special school was worse than that of those in mainstream education (with or without extra help). Parents of $60 \%$ of index children in mainstream schools rated their child as having normal behaviour compared with $31 \%$ of those at special school (RR 1.07, CI 1.02 to $1.12, \mathrm{p}=0.001)$. Similarly, when assessed by teachers, $68 \%$ of index cases in a mainstream school were scored as normal compared with $34 \%$ at special schools (RR 1.11, CI 1.04 to $1.17, \mathrm{p}<0.001)$.

There was no significant difference in the behaviour between the 103 children who had had meningitis during the first month of life and the 634 who had had postneonatal meningitis. There was no difference in behaviour between boys and girls, except that all eight children excluded from school were boys.
Comparing the total deviance scores where both teachers and parents had replied (table 4), 36\% of teachers and parents rated the index child as normal compared with $50 \%$ of those of a control child $(\mathrm{p}<0.001)$. Index children $(18 \%)$ were more than twice as likely to be rated as not having normal behaviour by both parents and teachers compared with controls (8\%) $(p<0.001)$. Twice as many index children $(14 \%)$ were rated as normal by teachers but not normal by their parents compared with the control group $(7 \%)(\mathrm{p}<0.001)$.

The "prosocial" scores (table 5), given by the parents, showed that $85 \%$ of index children and $91 \%$ of controls were rated by their parents as having normal positive social attributes, (RR 0.82 , CI 0.73 to $0.91 ; \chi^{2} 9.8$ and $\mathrm{p}<0.05$ ). These values fell to $63 \%$ and $71 \%$ respectively when scored by teachers (RR 0.88 , CI 0.80 to $0.98 ; \chi^{2} 5.4$ and $\mathrm{p}<0.05$ ). There was a significant difference between the parent $(85 \%)$ and teacher $(63 \%)$ rating of the index cases (RR 1.82, CI 1.55 to $\left.2.13, \chi^{2} 79.6, \mathrm{p}<0.001\right)$ and a similar difference between control parent $(91 \%)$ and teacher $(71 \%)$ ratings (RR 2.15, CI 1.66 to $2.78, \chi^{2} 56.8$ and $\mathrm{p}<0.001$ ).

Table 6 has been compiled from the classifications of disability at age 5 and information from the present study on the type of school attended. Of the 517 index children who had no or mild problems aged 5,94\% are in a mainstream school without extra help, 20 are receiving extra help at school, and three are in a special school. Of the 77 who were

\begin{tabular}{|c|c|c|c|c|c|}
\hline \multirow[b]{2}{*}{$\begin{array}{l}\text { Outcome at } 5 \\
\text { years }\end{array}$} & \multicolumn{5}{|c|}{ Type of schooling at age 13 years } \\
\hline & $\begin{array}{l}\text { Mainstream } \\
\text { school } \\
\mathrm{n}\end{array}$ & $\begin{array}{l}\text { Help at } \\
\text { school } \\
n\end{array}$ & $\begin{array}{l}\text { Special } \\
\text { school } \\
\mathrm{n}\end{array}$ & $\begin{array}{l}\text { Excluded } \\
\mathrm{n}\end{array}$ & $\begin{array}{l}\text { No information } \\
n\end{array}$ \\
\hline \multicolumn{6}{|l|}{ Index children } \\
\hline No problems & 314 & 11 & 1 & 6 & 72 \\
\hline Mild & 172 & 9 & 2 & 2 & 31 \\
\hline Moderate & 61 & 5 & 11 & 0 & 9 \\
\hline Severe & 3 & 3 & 25 & 0 & 0 \\
\hline Total & 550 & 28 & 39 & 8 & 112 \\
\hline \multicolumn{6}{|l|}{ Control children } \\
\hline No problems & 283 & 3 & 1 & & 82 \\
\hline Mild & 83 & 4 & 0 & & 22 \\
\hline Moderate & 1 & 1 & 0 & & 0 \\
\hline Total & 367 & 8 & 1 & & 104 \\
\hline
\end{tabular}


classified as having moderate problems aged 5, 61 are in a mainstream school without extra help, five are receiving extra help at school, and 11 attend a special school. Of the 31 severely affected children, 25 (81\%) are at a special school and six attend a mainstream school (three with and three without extra help). Of the 64 children who were classified as moderately or severely affected at age 5 but who attend a mainstream school, 52\% were rated as having behavioural problems by their parents and $35 \%$ by their teachers. The eight excluded children had been assessed as having no or mild problems. Of the 39 in a special school, 36 were assessed as having severe or moderate problems at age 5 .

\section{DISCUSSION}

The Strengths and Difficulties Questionnaire $(\mathrm{SDQ})^{4}{ }^{7}$ provides a quick and effective means of measuring behaviour in teenage children. In the present study, where direct assessment of the 997 children would not have been possible, the SDQ enabled parents and teachers easily to report their observations. It is clear, given the high response rate, that neither parents nor teachers had difficulty in completing the questionnaire. It is noteworthy that only $84 \%$ of index case parents and $78 \%$ of control parents gave permission for us to send the questionnaire to the child's teacher.

The educational requirements of children who have suffered from meningitis in infancy are clearly different from those who have not (table 1). The division of index cases into "complicated" and "uncomplicated" meningitis shows that there is an additional burden carried by children who had pyrexia $\left(>40^{\circ} \mathrm{C}\right)$, convulsions, relapse, etc during their meningitic episode.

SDQ responses by parents and teachers of control children gave very similar results for total deviance: $79 \%$ and $77 \%$ respectively classified the control children as "normal". The total deviance scores for index cases were significantly higher than for the controls when assessed by either parent or teacher. Parents of the index cases, whether "complicated" or "uncomplicated", perceived problems more often than the teachers. When assessed by teachers, $65 \%$ of index children were scored as normal compared to $77 \%$ of control children.

Impact score results for the control group-that is, how the children function in their surroundings, gave a different picture. While $10 \%$ of responses from parents gave their child a "not normal" score, the corresponding teachers classified $24 \%$ as "not normal". A similar situation existed in the assessment of index cases, but the differences between parents and teachers were not so marked. Both parents and teachers recognised significantly more problems in index children.

Among control children $91 \%$ had normal social skills at 13 years of age (prosocial scores) as judged by their parents (table $5)$. In contrast the teachers of these children only considered $71 \%$ to have normal skills. A similar difference existed among the index cases where $85 \%$ of parents and $63 \%$ of teachers considered them to have normal social skills. The difference between index cases and controls was less marked for social skills than for total deviance and impact scores.

Teenage behaviour is a complex issue, but of great importance to the families it affects. This is borne out by the fact that $74 \%$ of families replied to our questionnaire 13 years after their child's initial illness. No account has been taken of any changes to the child's home circumstances that may have occurred in the families since the child's birth, or of the possible effects such changes might have had on their behaviour. We have assumed that as the numbers of children studied are large, these life changes would have been equally frequent in each group. There were 64 index children who had been identified as having moderate or severe problems at 5 years and who were attending a mainstream school at age 13 years. Parents rated $52 \%$ of these children as having behavioural problems, and teachers $35 \%$. This would indicate that perhaps some of these children needed extra help at school.
There were 258 index families who were traced, but declined to participate in this study. Twenty nine children $(11 \%)$ had been assessed as having moderate or severe problems at the five year follow up. These problems may have burdened the families sufficiently to have discouraged them from participating in the study. There are very few published reports on the long term effects of infantile meningitis on child behaviour, and these involve only a small number of cases. Grimwood and colleagues ${ }^{89}$ reported on a longitudinal study of 158 cases of paediatric meningitis. At a mean of 8.4 years after the acute episode, 130 survivors, together with grade and sex matched controls, were assessed for a wide range of sequelae. The authors concluded that a quarter of index cases, compared to $7 \%$ of controls, had either serious or disabling sequelae or a functionally important behaviour disorder that affected academic progress. In a second follow up study at a mean of 12 years after the meningitic episode the index cases were still at a greater risk of disability than the controls. Children who had had acute neurological complications had more sequelae than uncomplicated cases or controls $(p<0.001)$. Behaviour scores of the index cases deteriorated between the first and second follow up study. Thus the results reported by Grimwood et al are in close agreement with those of the present study. Klinger and colleagues ${ }^{10}$ suggested that most infants at risk of an adverse outcome following bacterial meningitis could be identified within 12 hours of admission. The predictive factors which they suggested are largely those that are associated with "complicated" meningitis. The implication that cases of "uncomplicated" meningitis do not also suffer from serious sequelae, albeit at a lower frequency, is at variance with our findings.

This study shows that 13 year old children who suffered from bacterial meningitis during the first year of life have significantly more behavioural problems than matched controls when assessed by both parents and teachers. When it comes to social skills the differences between the two groups are less marked.

\section{ACKNOWLEDGEMENTS}

We thank the charity Action Research for funding this work and also the Al-Fayed Charitable Foundation for their initial help. We also thank the general practitioners and relevant health authorities in helping us trace the children, and all the parents and teachers who completed the questionnaires.

\section{Authors' affiliations}

S Halket, J de Louvois, D E Holt, D Harvey, Department of Paediatrics, Imperial College School of Medicine, Hammersmith Hospital, London, UK

\section{REFERENCES}

1 de Louvois J, Blackbourn J, Hurley R, et al. Infantile meningitis in England and Wales: a two year study. Arch Dis Child 1991;66:603-7.

2 Bedford $\mathbf{H}$, de Louvois J, Halket S, et al. A prospective study of meningitis in infancy in England and Wales: a five-year follow-up. BM 2001:323:533-6.

3 Stevens J, Harvey DR, Kent A, et al. Cognitive outcome at nine years of age of neonatal meningitis. Arch Dis Child 1999;80:A69

4 Goodman $\mathbf{R}$. The extended version of the Strengths and Difficulties Questionnaire as a guide to child psychiatric caseness and consequent burden. J Child Psychol Psychiatry 1999;40:791-9.

5 Elander J, Rutter M. Use and development of the Rutter Parents' and Teachers' Scales. Int J Methods Psych Res 1995;5:1-16.

6 Achenbach TM. Manual for the Child Behavior Checklist/4-18 and 1991 profile. Burlington, VT: University of Vermont Department of Psychiatry, 1991

7 Goodman R, Scott S. Comparing the Strengths and Difficulties Questionnaire and the Child Behaviour Checklist: is small beautiful? J Abnorm Child Psychol 1999;27:17-24.

8 Grimwood K, Anderson VA, Bond L, et al. Adverse outcomes of bacterial meningitis in school-age survivors. Pediatrics 1995;95:646-56.

9 Grimwood K, Anderson P, Anderson V, et al. Twelve year outcomes following bacterial meningitis: further evidence for persisting effects. Arch Dis Child 2000:83:111-16.

10 Klinger G, Chin CN, Beyene J, et al. Predicting the outcome of neonatal bacterial meningitis. Pediatrics 2000;106:477-82. 